\title{
Knowledge, Attitude and Practice of Family Planning Methods among Pregnant Women Attending Antenatal Clinic at Six Health Facilities in Rwanda
}

\author{
Habimana Emmanuel ${ }^{1 *}$, Rulisa Stephen ${ }^{2,3}$ and Rahel Ghebre ${ }^{4}$ \\ ${ }^{1}$ University of Rwanda, School of Medicine and Pharmacy, Kigali, Rwanda \\ ${ }^{2}$ Department of Obstetrics and Gynecology, University of Rwanda, School of Medicine and \\ Pharmacy, Kigali, Rwanda \\ ${ }^{3}$ School of Medicine and Pharmacy, University of Rwanda, Kigali, Rwanda \\ ${ }^{4}$ Gynecology Oncology Department, University of Minnesota, USA \\ *Corresponding author
}

\section{Keywords}

Areca nut, UHPLC,

Redox titration,

Vitamin $\mathrm{B}_{6}$,

Vitamin $\mathrm{C}$

\section{Article Info}

Accepted:

07 April 2018

Available Online:

10 May 2018

\section{A B S T R A C T}

The fertility rate in Rwanda decreased from 6.1 in 2005 to 4.6 in 2010 and to 4.2 in 2015. Widespread use of contraceptives has played a main role in this decrease. A cross sectional study was conducted on knowledge, attitude and practices of family planning methods on 426 pregnant women attending antenatal clinic in six health facilities in Rwanda. To assess the knowledge, attitude and practice of family planning methods and to determine the past and future intent of post-partum contraceptive use and factors associated with discontinuation of family planning methods among pregnant women attending antenatal clinic in Rwanda. A systematic random sampling method was used to select pregnant women who came for antenatal in each site. Data was collected using a standardized questionnaire and entered into a database. Chisquare tests were used for comparison and correlation between variables. $\mathrm{P}<0.05$ was considered statistically significant. $94.1 \%$ pregnant women attending antenatal clinic in Rwanda are familiar with at least 2-3 family planning methods with low knowledge about LARCs. $62.7 \%$ used modern contraceptive methods prior to the current pregnancy. Depoprovera, pills and Jadelle were the most used modern family planning methods. $91.1 \%$ of pregnant women intend to use modern contraceptive methods postpartum, mainly Jadelle, Depoprovera, and IUD. Higher number of gravidity and living children and occupation were found to be associated with the past contraceptive methods use and intent of post-partum contraceptive use. Fear of Side effects, desire for additional children and husband or sexual partner decision were found to be associated with the no use of contraceptive. Contraceptive awareness and attitude amongst pregnant women attending antenatal clinic in Rwanda was excellent (94.1\%) with fair use $(62.7 \%)$ of available methods. Barriers on no use of contraceptive methods should be addressed individually. 


\section{Introduction}

Rwanda has experienced a slight decrease of fertility rate, however, it is still high compared to the rest of the world. The fertility rate in Rwanda decreased from 6.1 in 2005 to 4.6 in 2010 and to 4.2 in 2015. Wide use of contraceptives has played the major role in this decrease (National Institute of Statistics of Rwanda, 2010; National Institute of Statistics of Rwanda 2014-2015) Recent data show that maternal mortality ratio in Rwanda has decreased from 750 to 540 per 100,000 livebirths in 2008, to 383 in 2010, and to 210 in 2015 (Health Management Information System). The percentage of women using contraceptive methods increased from $10 \%$ in 2004, 27\% in 2007 to $53 \%$ in 2015. Ensuring supply and availability of contraceptive methods will allow the fertility rate to continue to decrease and for family size to be planned. Awareness of people's attitudes and perceptions is very crucial, their attitude and adherence to contraception were found to play an important role in reducing unintended pregnancies. Different DHS (Demographic and Health Survey) in RWANDA show that the use of modern contraceptive methods has increased at around ten times, 4\%, 10\%, 27\%, $45 \%$ and $47 \%$ from RDHS (Rwanda Demographic and Health Survey) 2000, RDHS 2005, IRDHS 2007/2008, RDHS 2010 and RDHS 2014-2015 respectively and awareness and cognitive barriers are among other barriers that are compromising important adherence (WHO 1990-2010; National Institute of Statistics of Rwanda, 2010; National Institute of Statistics of Rwanda 2014-2015; WHO, 2013; Population Division, 2012).

Assessment of the contraceptive use continuation, switching and failure are very sensitive determinants of how well programs are responding to the family planning needs of women and couples. It will also reveal what is going well and what is going poorly in the knowledge of contraceptive users, their education, and gap in services they receive.

Studies showed that different areas in any health facilities can work as place where family planning methods can be discussed, especially in Prenatal care clinics but also some other places are source of information like teaching and classroom discussion (Oluwasanmi et al., 2011; Anthony, 2003).

Family planning is one of the interventions that can promote poverty reduction and socioeconomic development of the country through limiting and spacing births (Ministry of Health, 2012; WHO, 2012).

Studies done in Nigeria and in Ethiopia showed that pregnant women have sufficient knowledge (80-95\%) with low practice of modern family planning. Mass media and health workers were the most common source of information. Birth spacing and limiting births as well reduction of maternal mortality were mainly identified as benefits of family planning. (Igwegbe et al., 2010; Ikechebelu et al., 2005; Tilahun et al., 2013; Takele et al., 2012)

Other studies studied barriers of modern contraceptive methods use and the main barriers have been identified to be poor knowledge of available methods, poor experience, fear of side effects, husband and partners decision, low education level and religious believes (Igwegbe et al., 2010; Noone, 2004; Alemayehu et al., 2012).

Studies done in Ethiopia on intention to use and demand of long acting and permanent contraceptive methods (LAPMs) and factors affecting it among married women revealed that intention to use LAPMs was $48.4 \%$, higher among women who knew at least one of LAPMs and women who do not want to 
have birth within the next 2 years and poor intention to use LAMP among women who perceive poor support from their husbands and those who perceive LAPMs are harmful for the womb. Participants expressed their on the return of fertility after using implants or IUCD (Intrauterine Contraceptive Device) as well as insertion and removal procedures. Despite of good intention, the demand and use of LAPMs were low in both studies (demand of $18.1 \%$ utilization of 8.7\%) (Gebremariam, 2014; Takele, 2012).

With this study, we aimed to gather a general picture of pregnant women's awareness of contraceptive options, past methods used, barriers to use and methods they plan to use after birth.

Results of this study will help health providers and policy makers identify where there is a gap in family planning services delivery and to help find a way to improve it. Results will be disseminated within different health facilities and will be presented in different conferences on health care delivery.

On the best of our knowledge there is no study in RWANDA that shows the current status on knowledge, attitude and practice of family planning among women and among pregnant women in particular and it is not well known the reason why the use of contraceptive methods is still at $52 \%$ while all methods are for free in public health facilities.

\section{Materials and Methods}

We evaluated the knowledge and attitude on available modern family planning methods, past and future intent of post-partum contraceptive use among pregnant women attending antenatal clinic in six health facility in Rwanda. We assessed also factors associated with no use and discontinuation of contraceptive method.
This study is a health facility based cross sectional, qualitative study design and was conducted in six health facilities in Rwanda including two referral hospitals, two district hospitals and two health centers, namely CHUB (A referral and University teaching hospital), KABUTARE District Hospital and RWANIRO health center located at Southern province; CHUK (a referral and a university teaching hospital), KIBAGABAGA District Hospital and MUHIMA Health Center located in KIGALI town. From the national health policy, all modern contraceptive methods have to be offered at the level of Health Center apart from irreversible permanent contraceptive methods, such as tubal ligation and vasectomy, but it is not always the case as they are also being offered at all level of health facilities. Beneficiaries of those methods have different economic and social classes from health centers to referral hospitals and from rural to urban area. So to decrease bias and confounder elements that arise from this difference, in this study a mixing of health facilities is being used where CHUB as referral hospital, KABUTARE as District hospital and RWANIRO as health center are representing health facilities in rural area; CHUK as a referral hospital, KIBAGABAGA as a district hospital and MUHIMA Health center are representing health facilities in urban area.

We included all women who came for antenatal care at a health facility included in the study within the study period and who consent to participate voluntarily regardless the gestation age and regardless of their parity and living children are included in this study.

Systematic random sampling method was used to select pregnant subjects of the study in six different sites during the study period. To reduce bias and to give an equal chance to all respondents to be selected; at each health facility in this study and for each day of 
antenatal consultation; for every five attendees of those who gave their consent to participate in this study a questionnaire and assistance are given by a data collector.

Data will were collected in a period of three months maximum of the same period for each site, this is from July to September 2015.

As this study is a population base cross sectional study, its sample was calculates used the following formula: $\mathrm{n} \geq \mathrm{Z}^{2}$ (P) $(1-\mathrm{P}) / \mathrm{d}^{2}$ where: $\mathrm{n}$ : the minimum size required

$\mathrm{Z}$ : Z- score corresponding to the level of confidence with which it is desired to be sure that true population lies with $\pm \mathrm{d} \%$ point of the sample estimate (unless otherwise noted, assume 2 sided test with $\alpha=0.05, Z=1.96$ )

P: Expected population proportion (unless otherwise noted, assume $\mathrm{P}=0.50$ to obtain the most conservative estimate for $n$ )

\section{d: Precision required}

Rwanda MDHS (mid demographic and helath survey) 2012 shows that the prevalence of contraceptive use is $52 \%$ and similar studies done elsewhere reveals around $80 \%$ as the knowledge of pregnant women on contraceptive methods. Based on those two figures our targetted sample would be 422pregnant women and 271 pregnant women from a prevalence of $52 \%$ and $80 \%$ of knowledge respectively.

We expanded the sample to 426 pregnant women-71 pregnant women from each health facility included in this study.

Data were collected using a chart of semistructured questions and the subject had to answer questions through a trained data collector on a preset questionnaire. Data collectors had a training of one day before starting data collection and each site had one data collector who stayed always present to handle any concern on the questionnaire from respondents.

Data collectors collected data on knowledge of contraception by asking the respondent to describe all contraceptive methods she knew and asking whether the respondent recognized it, used it and if she plans to use it, when she think it is a good time to start contraception after birth and barriers on compliance were also collected. Information was collected on 11 modern family planning methods: female and male sterilisation, pills, intrauterine devices (IUDs), injectables, implants, male and female condoms, lactational amenorrhoea method (LAM), emergency contraception, and Standard Days Method (SDM).

Data was collected using standardized questionnaire and database created using EPIDATA version 3.1 and will exported into STATA 13 for analysis.

Chi-squared tests will be used for multivariate analysis for comparison and correlation between knowledge, attitudes, use of contraceptive methods. Probabilities $\mathrm{P}<0.05$ will be considered for significant statistical difference.

In this study, the knowledge of our respondents of family planning methods was graded as follow:

For all respondents who do not know any modern contraceptive methods, her Knowledge will be considered as very poor knowledge and for all those who knew only one method their knowledge is considered as poor knowledge

If Percentage of respondents who know at least two methods is less than $60 \%$, this will be considered as poor knowledge, 
If Percentage of respondents who know at least two methods is between $60-69 \%$, this will be considered as fair knowledge.

If Percentage of respondents who know at least two methods is $70-80 \%$, this is satisfactory knowledge

If Percentage of respondents who know at least two methods is more than $80 \%$, this is excellent knowledge.

In this study, as the subjects were contacted and interviewed, all participants gave their consent before enrolling. Its proposal protocol was approved by CMHS/UR (College of Medicine and Health Sciences) Institutional Review Board, CHUK and CHUB Institutional Review Board. Permission from relevant authorities of different sites was obtained before starting data collection.To ensure confidentiality of data given by participants; patient identifiers, such as name and address, were not collected. Data extraction was conducted by a trained health professional (a midwife, an intern, medical student or medical doctor) who are trained on medical research ethics.

\section{Results and Discussion}

In this study 426 pregnant women were included through systematic random sampling where after five pregnant women attending antenatal clinic in each of six health facilities one of them is recruted. 71 pregnant women were recruted in each health facilities.

The mean age of respondents was 27year-old, the youngest woman was 17year-old and the oldest was 42year-old. Respondents were mainly of 25-29year-old, 30-35year-old and 20-24year-old groups as they were $31.9 \%$, $25.4 \%$ and $22.5 \%$ of all sample size respectively. Most of the women were of primary level of education (40.61\%), followed by secondary $(30.99 \%)$ and higher level of education $(22.07 \%)$ respectively. The most common religions amongst the participants were catholic and protestant on almost equal proportion (40.85\% and $40.38 \%$ respectively), followed by adventists (12.21). Most of them were farmers and of no formal job on almost the same proportion $(34.51 \%$ and $31.69 \%$ repectively) followed by privates and public servants respectively (20.66\% and $13.15 \%)$. Most of the respondents in this study were having so far 1-3 pregnancies (72.07\%) followed by those of 4-6 pregnancies $(26.53 \%)$ and most of them were having 1-3 children $(62.44 \%)$ and $23.47 \%$ were with no child (Table 1).

Results of this study shows that ppregnant women attending antenatal clinic in Rwanda have excellent knowledge of available modern family planning methods, as $94.09 \%$ (401/426) pregnant women know at least 2-3 family planning methods. Implants (Jadelle), IUD, Pills and injectables (Depoprovera) were reported to be known by most of respondents while the fewest number of respondents knew about emergency contraception. When we subgroup respondents in small groups, we find that most of respondents have fair to good knowledge on available modern family planning methods as $51.4 \%(219 / 426)$ of them know 4-5modern contraceptive methods over 11 methods investigated while $34.50 \%$ (147/426) of them know 2-3methods over 11 methods. However, only 31.9\% (136/426) of respondents had no knowledge of longacting reversible contraceptive methods compared to $13.83 \%(59 / 426)$ and $8.19 \%$ (35/426) who knew only Jadelle and IUD respectively and separately. Only $1.88 \%$ (8/426) of respondents know both long-acting reversible contraceptive methods (IUD and Jadelle). Most of respondents know the importance of modern family planning methods as $88.5 \%$ (377/426) know at least two important uses of family planning methods. 
Birth spacing was reported by most of the repondents $78.4 \%(334 / 426)$ as importance of family planning methods use followed by improving life of the mother and the baby $43.90 \%$ (187/426) and prevention of unwanted pregnancy $23.24 \%$ (99/426). More than a half of respondents know at least two sources of information on family planning methods $55.17 \%(325 / 426)$ and $41.55 \% \quad(177 / 426)$ know at least one source of information.

Health facilities were reported by most of the respondents as the first source of information, followed by Community Health Workers and media respectively (Table 2 ).

When we assessed attitude, consideration and appreciation of modern family planning methods use by respondents, this study showed that most of repondents appreciate modern family planning methods use as 92.96 $\%$ (398/426) reported that using them is very important. And accessibility to family planning methods is granted as $80.52 \%$ (343/426) of respondents strongly agree with the fact that they can have access to all contraceptive methods and given by competent health care providers.

Concerning husband and sexual partner involvement this study shows that most of pregnant women $72.30 \%$ (308/426) reported that their husbands and sexual partners support modern contraceptive use and $43.66 \%$ (186/426) of respondents strongly disagree with the fact that a husband or sexual partner can decide whether or not to use any contraceptive method, however $19.48 \%$ (83/426) strongly agree that their husbands or sexual partners can decide for them. Almost a half of the respondents $46.47 \%$ (198/426) strongly agree with the fact that they can not decide themsleves to use any form of modern contraceptive methods without consulting their husbands or sexual partners while 19.01 $\%(81 / 426)$ can decide themselves to use any form of modern contraceptive methods on their choice. In this study most of pregnant women have a positive attitude as $38.49 \%$ (164/426) strongly desagree with the fact that LARC can cause harm to someone's uterus, $20.66 \%$ (88/426) agree with it while $21.13 \%$ (90/426) are not sure of either LARCs are harmful or not to the uterus (Table 3 ).

In total $62.67 \%(267 / 426)$ respondents used contraceptive methods before getting the current pregnancy. While $37.33 \%$ (159/426) respondents did not use any contraceptive due to various reasons. Depoprovera, pills and Jadelle were the most used modern family planning methods respectively.Reasons of no use of modern family planning methods are mainy fear of side effects and religious believes. Higher number of gravidity, higher number of living children, and occupation were found to be associated with the past contraceptive methods use $(p<0.01)$. Side effects, more children and husband or sexual partner decision were found to be associated with the no use of contraceptive $(\mathrm{p}<0.01)$.

When we compare past contraceptive use among health facilities included in this study, we found that pregnant women in referral hospitals (CHUK and CHUB) were less likely to use contraceptive methods in the past while pregnant women in District Hospitals and Health Centers were using various form of contraceptions $(\mathrm{p}<0.01)$.

There was no significant association between religion and the past contraceptive use among respondents $(\mathrm{p}=0.41)$ (Table 4$)$.

This study showed that most of the respondents stopped or changed the contraceptive methods because they wanted another child $40.38 \%$ (172/426), 35.45\% (151/426) were not using any form of modern contraceptive methods and $17.37 \%$ (74/426) stopped contraceptive methods due to severe 
side effects and $4.46 \%$ (19/426) pregnant women report the current pregnancy is a result of failed contraceptive methods (Table 4).

Most of respondents $37.56 \%$ (160/426) plan to have another pregnancy in more than 5years, $23.71 \%(101 / 426)$ plan no further children and $18.31 \%(78 / 426)$ are not sure of the time they will have another pregnancy. A higher number of living children was associated with planning another pregnancy later than those with lower number of living children $(\mathrm{P}<0.01)$. Pregnant women with 4-6 living children are most likely to plan the next pregnancy later (>5years) and if not they do not desire further childbearing and also most likely to use permanent contraceptive methods $(\mathrm{p}<0.01)$. The future intent on contraceptive methods is mainly based on Jadelle, Depoprovera, and IUD use as respondents plan to use those methods at a rate of $24.18 \%$ (103/426), 23.24\% (99/426) and $14.32 \%$ (61/426) respectively. Some of respondents deny any contraceptive methods use $4.93 \%$ (21/426) while $3.29 \% \quad(14 / 426)$ of all respondents plan to use irreversible contraceptive methods (Bilateral tubal ligation). Higher number of gravidity and living children were associated with use of contraceptive methods in the future $(\mathrm{p}=0.04)$. Pregnant women with one to three living children were most likely to use contraceptive methods in the future as compared to those with no living child. There is an association between a Past contraceptive method use with an intent of post-partum contraceptive methods use among pregnant women, as those who used any form of contraceptive methods are most likely to use it again in the future $(\mathrm{p}<0.01)$. There is also an association between reason of family planning methods discontinuation with the intent of post-Prtum contraceptive use. Pregnant women who stoppped the past contraception as they wanted another child are most likely to use a form of modern contraception, and those who reported to stop the method due to side effects are less likely to use it in the post-partum $(\mathrm{P}<0.01)$. Most of respondents know on almost equal proportion that contraception can be started immediately after delivery and within 6weeks post-partum, 28.17\% (120/426) and $30.99 \%(132 / 426)$ respectively). While $17.37 \%(74 / 426)$ of respondents know that contraception can be started by the time they resume menses, $14.55 \%$ (62/426) of respondents do not know when to start contraception in post-partum. Pregnant women in referral hospitals are less likely to know exactly the best time to start contraception in post-partum than those in district hospitals and Health Centers $(\mathrm{p}=0.01)$. Most of respondents $82.68 \%$ (339/426) know that they will get their contraceptive method from public health facilities, 3.17\% (13/426) will get it from private health facilities and $(28 / 426=6.6 \%)$ will get them from community health workers (Table 5).

Most pregnant women attending antenatal clinic in Rwanda have excellent knowledge of available modern family planning methods as 94.09\% know at least 2-3 family planning methods. Implants (Jadelle), IUD, Pills and injectables (Depoprovera) were reported to be known by most of respondents while emergency contraception was the last one to be known. This knowledge is greater than that found in studies conducted in Nigeria and Ethiopia. Those studies report knowledge of available modern family planning methods to be at around $80 \%$ and the Rwanda DHS2010 reported that knowledge of at least one method was universal for both women and men (National Institute of Statistics of Rwanda, 2010; Ikechebelu et al., 2005; Tilahun et al., 2013). Most commonly known modern contraceptive among pregnant women are similar to findings from Rwanda DHS 2010 and DHS 2014-2015 (National Institute of Statistics of Rwanda, 2010; National Institute of Statistics of Rwanda, 2014-2015). 
Table.1 Socio-demographic characteristics of respondents $(\mathrm{N}=426)$

\begin{tabular}{|c|c|c|}
\hline Age of respondents (years) & Number & Percentage \\
\hline $15-19$ & 18 & 4.23 \\
\hline $20-24$ & 96 & 22.54 \\
\hline $25-29$ & 136 & 31.92 \\
\hline $30-34$ & 108 & 25.35 \\
\hline $35-39$ & 56 & 13.15 \\
\hline$\geq 40$ & 12 & 2.82 \\
\hline \multicolumn{3}{|l|}{ Religion } \\
\hline Catholic & 174 & 40.85 \\
\hline Adventist & 52 & 12.21 \\
\hline Protestant & 172 & 40.38 \\
\hline Islam & 18 & 4.23 \\
\hline Other & 10 & 2.35 \\
\hline \multicolumn{3}{|l|}{ Occupation } \\
\hline No formal Job & 135 & 31.69 \\
\hline Public services & 56 & 13.15 \\
\hline Farmer & 147 & 34.51 \\
\hline Private & 88 & 20.66 \\
\hline \multicolumn{3}{|l|}{ Living children } \\
\hline 0 & 100 & 23.47 \\
\hline $1-3$ & 266 & 62.44 \\
\hline $4-6$ & 39 & 9.15 \\
\hline$>6$ & 21 & 4.93 \\
\hline
\end{tabular}


Table. 2 Knowledge of respondents on available modern contraceptive methods

\begin{tabular}{|c|c|c|}
\hline $\begin{array}{l}\text { Kinds of contraceptive methods known by } \\
\text { respondents }\end{array}$ & Number & Percentage \\
\hline No methods known (Very poor knowledge) & 9 & 2.11 \\
\hline One method known (Poor knowledge) & 16 & 3.80 \\
\hline $\begin{array}{l}\text { 2-3 methods known (Fair } \\
\text { knowledge) }\end{array}$ & 147 & 34.50 \\
\hline $\begin{array}{l}\text { At least two modern } 4-5 \quad \text { methods known(Good } \\
\text { FP methods known }\end{array}$ & 219 & 51.40 \\
\hline $\begin{array}{l}\text { 6-9 methods known (all) (very } \\
\text { good knowledge) }\end{array}$ & 20 & 4.70 \\
\hline $\begin{array}{l}\text { All methods known (Excellent } \\
\text { knowledge) }\end{array}$ & 15 & 3.52 \\
\hline \multicolumn{3}{|l|}{ Most effective methods } \\
\hline IUDs & 35 & 8.19 \\
\hline IUDs, depoprovera & 2 & 0.47 \\
\hline IUDs, jadelle & 8 & 1.88 \\
\hline LAM & 3 & 0.70 \\
\hline Condom, SDM & 49 & 11.5 \\
\hline Depoprovera & 88 & 20.66 \\
\hline I do not know & 136 & 31.92 \\
\hline Jadelle & 59 & 13.83 \\
\hline Pills & 30 & 7.04 \\
\hline Pills, depoprovera & 6 & 1.41 \\
\hline tubal ligation, vasectomy & 10 & 2.35 \\
\hline \multicolumn{3}{|l|}{ Importance of family planning } \\
\hline No importance & 11 & 2.58 \\
\hline One important use of family planning & 38 & 8.92 \\
\hline $\begin{array}{l}\text { At least two important use of family planning } \\
\text { methods }\end{array}$ & 377 & 88.50 \\
\hline \multicolumn{3}{|l|}{ Source of information on family planning methods } \\
\hline No known source of information & 14 & 3.28 \\
\hline One source of information & 177 & 41.55 \\
\hline At least two sources of information & 235 & 55.17 \\
\hline
\end{tabular}


Table.3 Attitudes on family planning methods by respondents $(n=426)$

\begin{tabular}{|l|c|c|}
\hline $\begin{array}{l}\text { Access to all contraceptive methods and given by } \\
\text { competent health care providers }\end{array}$ & Number & Percentage \\
\hline Strongly agree & 343 & 80.52 \\
\hline Agree & 36 & 8.45 \\
\hline Not agree nor desagree & 37 & 8.69 \\
\hline Desagree & 5 & 1.17 \\
\hline Strongly desagree & 5 & 1.17 \\
\hline $\begin{array}{l}\text { My husband or partner supports } \text { modern } \\
\text { contraceptives use }\end{array}$ & & \\
\hline Strongly agree & 308 & 72.30 \\
\hline Agree & 41 & 9.62 \\
\hline Not agree nor disagree & 47 & 11.03 \\
\hline Disagree & 16 & 3.76 \\
\hline Strongly disagree & 14 & 3.29 \\
\hline A husband or sexual partner decides whether or not \\
to use a contraceptive method
\end{tabular}


Table.4 Past contraceptive use among pregnant women and reason of discontinuation

\begin{tabular}{|c|c|c|}
\hline $\begin{array}{l}\text { Kind of contraceptive methods used } \\
\text { prior to the current pregnancy }\end{array}$ & Number & Percentage \\
\hline Bilateral tubal ligation and it failed & 1 & 0.23 \\
\hline Pills & 55 & 12.91 \\
\hline IUD & 14 & 3.29 \\
\hline Depoprovera & 96 & 22.54 \\
\hline Jadelle & 49 & 11.50 \\
\hline Condoms & 13 & 3.05 \\
\hline LAM & 1 & 0.23 \\
\hline Standard Days Method (SDM) & 38 & 8.92 \\
\hline Subtotal 1 & 267 & 62.67 \\
\hline $\begin{array}{l}\text { Respondents who did not use any } \\
\text { contraception fear of side effects. }\end{array}$ & 2 & 0.47 \\
\hline $\begin{array}{l}\text { Respondents who did not use any } \\
\text { contraception with no clear reason }\end{array}$ & 151 & 35.45 \\
\hline $\begin{array}{l}\text { Respondents who did not use any } \\
\text { contraception because of Religion } \\
\text { believes }\end{array}$ & 6 & 1.41 \\
\hline Subtotal 2 & 159 & 37.33 \\
\hline $\begin{array}{l}\text { Reason of contraception method } \\
\text { discontinuation }\end{array}$ & Frequency & Percentage \\
\hline Wanted another child & 172 & 40.38 \\
\hline Severe side effects & 74 & 17.37 \\
\hline Not available at health facilities & 2 & 0.47 \\
\hline Lack of enough information & 2 & 0.47 \\
\hline Religion believes & 2 & 0.47 \\
\hline Side effects & 4 & 0.94 \\
\hline No use of contraceptive methods & 151 & 35.45 \\
\hline Contraceptive methods failed & 19 & 4.46 \\
\hline
\end{tabular}


Table.5 Plan for next pregancy, Intent of post-partum contraceptive method use, time to start contraceptive methods in postpartum and source of family planning methods according to our respondents $(n=426)$

\begin{tabular}{|c|c|c|}
\hline Time for next pregnancy & Frequency & Percentage \\
\hline Within 2years & 22 & 5.16 \\
\hline 3years & 65 & 15.26 \\
\hline$>$ yyears & 160 & 37.56 \\
\hline I do not need another child & 101 & 23.71 \\
\hline I do not know & 78 & 18.31 \\
\hline \multicolumn{3}{|l|}{ Future Intents } \\
\hline Bilateral tubal ligation & 14 & 3.29 \\
\hline $\begin{array}{l}\text { Never use any contraceptive } \\
\text { method }\end{array}$ & 21 & 4.93 \\
\hline Pills & 35 & 8.22 \\
\hline IUD & 61 & 14.32 \\
\hline Depoprovera & 99 & 23.24 \\
\hline Jadelle & 103 & 24.18 \\
\hline Condoms & 20 & 4.69 \\
\hline $\begin{array}{l}\text { Lactational amenorrhoea } \\
\text { method (LAM) }\end{array}$ & 3 & 0.70 \\
\hline Standard Days Method (SDM) & 53 & 12.44 \\
\hline Any other method & 17 & 3.99 \\
\hline \multicolumn{3}{|l|}{$\begin{array}{l}\text { Time to start contraceptive } \\
\text { methods }\end{array}$} \\
\hline $\begin{array}{l}\text { Within } 6 \text { weeks (1month and } \\
2 \text { weeks) postpartum }\end{array}$ & 132 & 30.99 \\
\hline Immediate in postpartum & 120 & 28.17 \\
\hline Within six month after birth & 38 & 8.92 \\
\hline By the time menses will return. & 74 & 17.37 \\
\hline I do not know & 62 & 14.55 \\
\hline
\end{tabular}


These findings are different from results of studies from Nigeria as for them the most known family planning methods were Billings/safe period (Ikechebelu et al., 2005; Tilahun et al., 2013).

This study finds that there is a big problem on the knowledge of respondents on the knowledge of long-acting reversible contraceptive methods as $31.92 \%$ of them do not know them while $13.83 \%$ and $8.19 \%$ report to know Jadelle and IUD respectively and separately and only $1.88 \%$ of respondents know both long-acting contraceptive methods. These findings are different from those from two studies from Ethiopia on Long acting and Reversible Contraceptive methods where one study (Tilahun et al., 2013) reveals that LAMPs were well known by women but another study in the same country reports a negative attitude towards practicing LAMPS (Alemayehu et al., 2012) (Table 2).

Findings of this study show that most of respondents know the importance of modern family planning methods as $88.50 \%$ know at least two important use of family planning methods. And Birth spacing was reported by most of the repondents $(334 / 426=78.4 \%)$ as importance of family planning followed by improving life of the mother and the baby $(187 / 426=43.90 \%)$,

$99 / 426=23.24 \%$

preventing unwanted pregnancy. Those findings are similar to those found in similar studies done in Nigeria and Ethiopia where they also reveal that birth spacing and limiting births were among other importance of family planning at a percentage of $72.9 \%$ and $40.6 \%$ respectively (National Institute of Statistics of Rwanda, 2010; National Institute of Statistics of Rwanda, 2014-2015; Gebremariam, 2014). Health facilities were reported by most of the respondents as the first source of information, followed by Community Health Workers and media respectively. Those findings are similar to those of various studies where mass media, health facilities and health workers are among other source of information (Oluwasanmi et al., 2011; Ferdous et al., 2012; Dieudonné Ndaruhuye et al., 2013; Ministry of Health, 2012).

In total 267 respondents $(62.67 \%)$ over 426 respondents used modern contraceptive methods before getting the current pregnancy. Depoprovera, pills and Jadelle were the most used modern family planning methods respectively. As we consider this percentage as the prevalence of family planning methods use among pregnant women attending antenatal clinic in health facilities in Rwanda, we find that this rate is greater than the rate of $45 \%$ of contraceptive methods use in Rwanda from DHS 2010 and 47\% in DHS 2014-2015 but those DHSs consider general population (National Institute of Statistics of Rwanda, 2010; National Institute of Statistics of Rwanda, 2014-2015). Pregnant women in Rwanda used Family Planning methods more compared to those in other studies where prevalence of contraceptive use was $25 \%$ for the study done in Nigeria and $43 \%$ in study done in Ethiopia (Igwegbe et al., 2010; Ikechebelu et al., 2005; Tilahun et al., 2013) When we compare past contraceptive use among health facilities included in this study, we found the opposite of one could expec ; pregnant women in referral hospitals (CHUK and CHUB) were less likely to use contraceptive methods in the past while pregnant women in District Hospitals and Health Centers were most likely to use various form of contraceptions $(\mathrm{p}<0.01)$. This association can be explained by the fact that all modern Family Planning Methods were mainly given for free at Health Centers and also Community Health Worker are trained in giving some contraceptive methods at village level like pills and injectables from Rwanda Ministry of Health Program called CBP (Community Based Provision Program) introduced in 2011. From District Hospitals to 
Referral Hospitals some price is applied for those receiving a contraceptive method there and moreover some of referral hospitals do not have Family Planning service apart (Ministry of Health, 2012).

Higher number of gravidity, higher number of living children, Occupation were found to be associated with the past contraceptive methods use $(p<0.01)$. Past family planning method use increased with the increase of gravidity and number of living children. Side effects, more children and husband or sexual partner decision were found to be associated with the no use of contraceptive $(\mathrm{p}<0.01)$. The use of contraceptive methods is decreasing among pregnant women who reported severe side effects, among pregnant women who desired more children and among those pregnant women whose husband or sexual partner decides for them to use or not a family planning method. There was no significant association between Religion, level of education and the past contraceptive use among respondents $(\mathrm{p}=0.41, \mathrm{p}=0.14)$. Those findings are similar to those of other studies done in other countries and even in Rwanda (Dieudonné Ndaruhuye et al., 2013; Ministry of Health, 2012; Igwegbe et al., 2010; Ikechebelu et al., 2005; Tilahun et al., 2013, Noone, 2004; Alemayehu et al., 2012).

Findings of this study reveals that apart from 21 pregnant women $(4.93 \%)$ who denied any modern contraceptive methods in post-partum and 17 pregnant women (3.99\%) who reported to use any other method rather than modern contraceptive methods, $91.08 \%$ of pregnant women tend to use any form of modern contraceptive methods. This is a very strong intent as the Rwanda Minitry of Health target of contraceptive methods use in 2018 is $70 \%$ and it is very important to pregnant women to start thinking and planning the contraceptive methods to be used after delivery as it is associated with the decrease of unintended pregnancy, improvement of maternal and child well being. And it should be discussed earlier in antenatal clinic (Huezo et al., 1993; Koenig et al., 1997; Brunie et al., 2013). This study also reveals that the future intent of post-partum contraceptive methods use is mainly based on Jadelle, Depoprovera, and IUD use as they plan to use those methods at a rate of $24.18 \%, 23.24 \%$ and $14.32 \%$ respectively. While $3.29 \%$ of all respondents plan to use irreversible contraceptive methods (Bilateral tubal ligation). From those figures, pregnant women in Rwanda have an excellent intent of post-partum contraceptive methods use as a big number of them tend to use LARCs (IUD and Jadelle) and even irreversible contraceptive methods when it is known that those are the most effective contraceptive methods. It is also supported by the fact that when pregnant women are having positive attitude on LARCs as when they were asked about their effects on the uterus, $38.49 \%$ strongly desagreed the fact that LARCs can harm someone's uterus. Their attitude is different from those of other studies done in different countries including two studies done in Ethiopia (Gebremariam, 2014; Takele et al., 2012). Higher number of gravidity and living children were associated with use of contraceptive methods in the future $(\mathrm{P}=$ 0.04). Pregnant women with one to three living children were most likely to use contraceptive methods in the future than those with no living child. There is an association between a Past contraceptive methods use with an intent of post-partum contraceptive methods use among pregnant women, as those who used any form of contraceptive methods are most likely to use it again in the future $(\mathrm{P}<0.001)$. There is also an association between reason of family planning methods discontinuation with the intent of post-Prtum contraceptive use. Pregnant women who stoppped the past contraception as they wanted another child are most likely to use a 
form of modern contraception, and those who reported to stop the method due to side effects are less likely to use it in the post-partum. Most of respondents know on almost equal proportion that contraception can be started immediately after delivery and within 6weeks post-partum (28.17\% and $30.99 \%$ respectively). While $17.37 \%$ of respondents know that contraception can be started by the time they resume menses, $14.55 \%$ of respondents do not know when to start contraception in post-partum. Pregnant women in referral hospitals are less likely to know exactly the best time to start contraception in post-partum than those in district hospitals and Health Centers $(\mathrm{P}=$ 0.01). These findings are similar to those of other studies like a study done by Noone, et $a l$. , that revealed that women choose a method or methods to prevent pregnancy based on their knowledge, experience, and evaluation of what would be the best fit within the context of their current life situation. (Noone, 2004) Other studies highlight the importance of counseling, education and strong family planning programs, a wide range of available methods, informed choice of method, quick start procedure, easy access and good follow up services to be associated with continued and satisfied use of a method (Huezo et al., 1993; Koenig et al., 1997; Cotten et al., 1992; Ali, 2001; Mohamed M. Ali, 2012; Brunie et al., 2013; Minstry of Health, 2012; MubitaNgoma and Kadantu, 2010; Stechna et al., 2013).

To the best of our knowledge, this is the first study in Rwanda to assess whether poor knowledge and negative attitudes of pregnant women inadvertently pose a barrier to widespread contraceptive use among them in particular and through the country in general. As our sample was chosen through systematic random sampling we cannot know if those pregnant women who did not participate in the study would give different answers or not and again we used different data collectors with their different understanding when helping a respondent on questionnaire and here a bias in selection may occur. We are not sure if it is true when a respondent says she used or she will use a contraceptive methods.

This study can give a general picture on the knowledge, attitude and practice of family planning methods among pregnant women in Rwanda as we used six heath facilities of different level of care (referral and district hospitals and Health centers), with different data collectors and data collection was done in different days of work and it included all socio-economic classes in Rwanda. Moreover there was no compensation for the participation.

There is a need of a large study in this area and especially on the knowledge, attitudes and practice of family planning methods among health professional in referral hospitals.

Severe side effects of contraceptive methods have to be addressed individually, couple education targetting husbands and sexual partners on family planning methods are needed and a study secondary to this one will be also good as it may show if really respondents use contraceptive methods they said they will use in post-partum.

Pregnant women in Rwanda have an excellent knowledge and attitude of available modern family planning but minimal use $(62.7 \%)$ compared to Rwanda Ministry of Health target by 2018 (70\%). Pills and injectables (Depoprovera) were reported to be known by most of respondents while emergency contraception was the last one to be known but their knowledge on LARCs (IUD and Jadelle) is still low. Being of health centers and distrit hospitals, age, number of number of living children, past contraceptive users 
and occupation of the repondents are factors associated with contraceptive use while severe side effects of modern contraceptive methods, desire of more children and husband or sexual partner decision for their wife and the inability of women to decide themselves to use or not a family planning method are factors associated with no use of modern contraceptive methods.

\section{Competing Interests}

The authors declare that they have no competing interests.

\section{Contribution to Authorship}

HE conceived the idea, developed study protocol, participated in data collection at CHUK and KIBAGABAGA and statistical analysis and preparation of the article.

SR conceived the idea, provided expert guidance, and contributed to the editing of the article.

RG provided reviewed the protocol, gave expert guidance and contributed the preparation of the article.

\section{Acknowledgement}

Special thanks go to Dr RULISA Stephen and Dr Rahel Ghabre for the support, advices and supervision of this work.

Particular thanks go to all Obstetricians and Gynecologists, General Practitioners, Midwives and Nurses in different Hospitals; for their valuable contribution in this study.

We thank all data collectors for their contribution for the accomplishment of this study, we extend our sincere thanks and profound appreciation.

\section{References}

Alemayehu M, Belachew T, Tilahun T., Factors associated with utilization of long acting and permanent contraceptive methods among married women of reproductive age in Mekelle town, Tigray region, north Ethiopia. BMC Pregnancy Childbirth. 2012 Jan 26; $12: 6$.

Ali MM. Quality of care and contraceptive pill discontinuation in rural Egypt. Journal of Biosocial Science, 2001, 33(2):161-72.

Anthony K. M. Delivering Family Planning Messages through Prenatal Care Clinics in Kumi District, Uganda. The International Electronic Journal of Health Education, 2003; 6: 34-40

Blanc AK, Curtis SL, Croft TN. Monitoring contraceptive continuation: links to fertility outcomes and quality of care. Studies in Family Planning, 2002, 33(2): 127-40.

Brunie A, Tolleym EE, Ngabo, F, Wesson, J, Chen, M. Getting to $70 \%$ : Barriers to modern contraceptive use for women in Rwanda. Int J Gynecol Obstet 2013; 123: Suppl.1: e11-e15.

Cotten $\mathrm{N}$ et al., Early discontinuation of contraceptive use in Niger and the Gambia. International family planning perspectives, 1992, 18:145-9.

Dieudonné Ndaruhuye M.D, Pierre Claver Rutayisire P.C, Umubyeyi A. Measuring the Success of Family Planning Initiatives in Rwanda: A Multivariate Decomposition Analysis. ICF International. Calverton, Maryland, USA. February 2013.

Ferdous J, Ahmed A, Dasgupta SK, Jahan M, Huda FA, Ronsmans C, Koblinsky M, Chowdhury ME. Occurrence and Determinants of Postpartum Maternal Morbidities and Disabilities among Women in Matlab, Bangladesh. $J$ 
Health Popul Nutr., 2012 Jun; 30(2): 143-58

Gebremariam A, Addissie A. Intention to use long acting and permanent contraceptive methods and factors affecting it among married women in Adigrat town, Tigray, Northern Ethiopia. Reprod Health. 2014 Mar 16;11(1):24.

Huezo $\mathrm{C}$ et al., Acceptability and continuation of use of contraceptive methods. In: Teoh ES, Ratnam SS, Macnaughton M, eds. General Gynaecology: Proceedings of the XIIIth World Congress of Gynaecology and Obstetrics. 1993: 1:111-135,Carnforth: Parthenon Publishing Group.

Igwegbe AO, Ugboaja JO, Monago EN. Knowledge and practice of family planning among antenatal care attendees at Nnewi, South east Nigeria. Niger Postgrad Med J. 2010 Dec; 17(4): 287 90.

Ikechebelu JI, Joe-Ikechebelu NN, Obiajulu FN. Knowledge, attitude and practice of family planning among Igbo women of south-eastern Nigeria. $J$ Obstet Gynaecol. 2005 Nov; 25(8):792-5.

Koenig MA, Hossain MB, Whittaker M. The influence of quality of care upon contraceptive use in rural Bangladesh. Studies in family planning, 1997, 28(4):278-89.

Ministry of Health, RWANDA. Family Planning strategic plan 2012-2016, December 2012

Minstry of Health 2012. Policy Family Planning 2012-2016. Kigali-Rwanda

Mohamed M. Ali, John Cleland, Iqbal H. Shah. Causes and consequences of contraceptive discontinuation: evidence from 60 Demographic and Health Surveys. World Health Organization 2012

Mubita-Ngoma C, and Kadantu MC. 2010. “ Knowlegde and use of modern family planning methods by rural women in Zambia." Curationis, 1(33): 17-22

National Institute of Statistics of Rwanda (NISR) (Rwanda), Ministry of Health (MOH) (Rwanda), and ICF International. Rwanda Demographic and Health Survey 2010. Calverton, Meryland, USA, NISR, MOH, ICF International

National Institute of Statistics of Rwanda (NISR) (Rwanda), Ministry of Health $(\mathrm{MOH})$ (Rwanda), Ministry of finance and economic planning(RWANDA) and ICF International. Rwanda Demographic and Health Survey 20142015. Calverton, Meryland, USA, NISR, MOH, ICF International

Noone J. Finding the best fit: a grounded theory of contraceptive decision making in women. Nurs Forum. 2004 Oct-Dec; 39(4):13-24.

Oluwasanmi L.A, Supa P, Karl P. Awareness and use of and barriers to family planning services among female university students in Lesotho. SAJOG, September 2011, Vol. 17, No. 3

Population Division, Department of Economic and Social Affairs, United Nations, World Population Prospects: The 2012 Revision.

Safe abortion: technical and policy guidance for health systems. Geneva, World Health Organization, forthcoming.

Stechna S1, Mravcak S, Schultz P, Santolaya J. The Quick Start Contraception Initiation Method during the 6-week postpartum visit: an efficacious way to improve contraception in Federally Qualified Health Centers. Contraception. 2013 Jul;88(1):160-3.

Takele A, Degu G, Yitayal M. Demand for long acting and permanent methods of contraceptives and factors for non-use among married women of Goba Town, Bale Zone, South East Ethiopia. Reprod 
Health. 2012 Oct 29;9:26. doi: WHO, UNICEF, UNFPA and The World 10.1186/1742-4755-9-26.

Tilahun T, Coene G et al., Family planning knowledge, attitude and practice among married couples in Jimma Zone, Ethiopia. PLoS One. 2013 Apr 23; 8(4): e61335. Bank estimates. Trends in maternal mortality: 1990 to 2010

WHO, World Health Statistics 2013.

WHO. Maternal mortality. Fact sheet $\mathrm{N}^{\circ} 348$, May 2012 (http://www.who.int/media centrelfactsheets/fs348/en/ seen on O7/102/2015)

\section{How to cite this article:}

Habimana Emmanuel, Rulisa Stephen and Rahel Ghebre. 2018. Knowledge, Attitude and Practice of Family Planning Methods among Pregnant Women Attending Antenatal Clinic at Six Health Facilities in Rwanda. Int.J.Curr.Microbiol.App.Sci. 7(05): 770-787. doi: https://doi.org/10.20546/ijcmas.2018.705.094 